

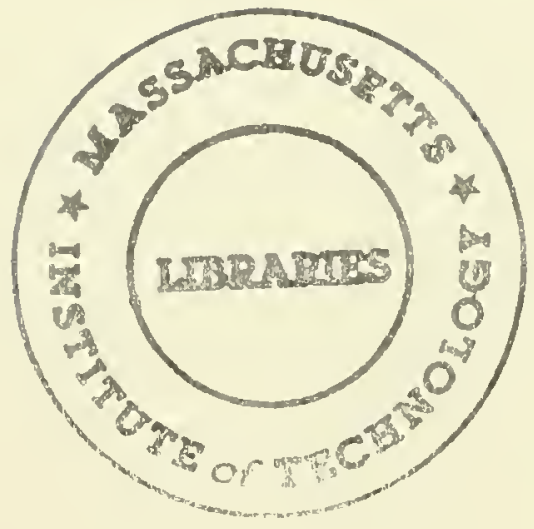






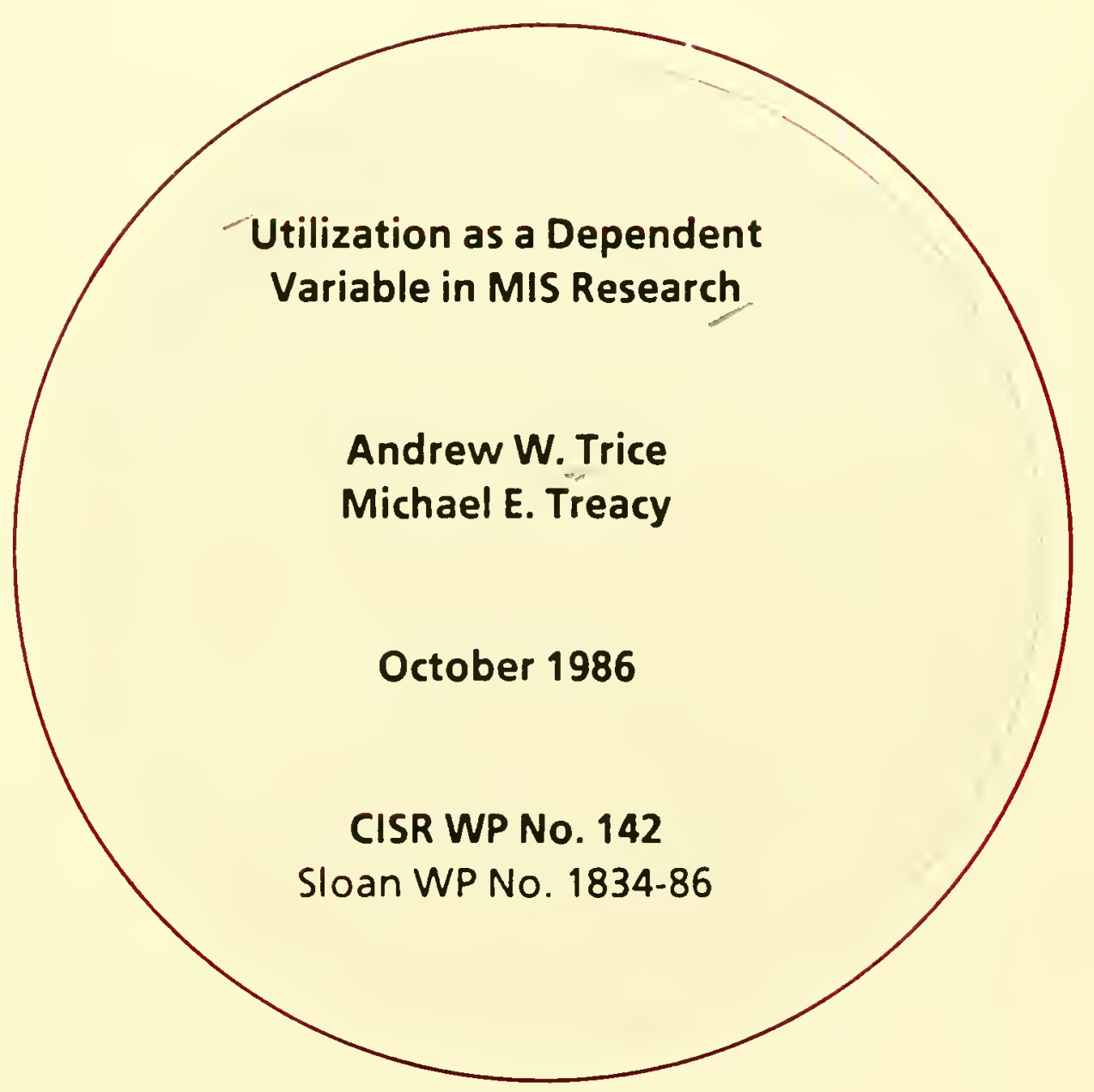

Center for Information Systems Research

Massachusetts Institute of Technology

Sloan School of Management

77 Massachusetts Avenue

Cambridge, Massachusetts, 02139 



\title{
Utilization as a Dependent Variable in MIS Research
}

\author{
Andrew W. Trice \\ Michael E. Treacy
}

October 1986

CISR WP No. 142

Sloan WP No. $1834-86$

๑ 1986 A.W. Trice and M. E. Treacy

To be presented at the Seventh Annual International Conference on Information Systems, December 14-17, 1986, San Diego, California

\footnotetext{
Center for Information Systems Research

Sloan School of Management

Massachusetts Institute of Technology
} 


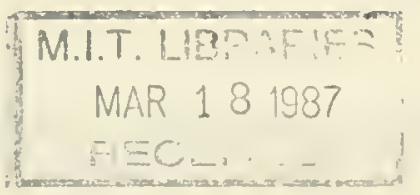




\title{
Utilization as a Dependent Variable in MIS Research
}

Andrew W. Trice and Michael E. Treacy

\begin{abstract}
Utilization of an information system is an important and frequently measured MIS variable, since use of a system is the conduit through which information technology can affect performance. This paper addresses measurement issues associated with utilization variables. The discussion is motivated by a review of the literature and an examination of three relevant reference theories. It is asserted that utilization can be measured effectively if the measures chosen correspond to the measures suggested by an appropriate reference theory.
\end{abstract}




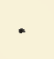

$$
\text { - }
$$




\section{Utilization as a Dependent Variable in MIS Research}

\section{Introduction}

The amount of use an individual, group, or organization makes of an information system is a key variable in MIS research. It is often used as an independent variable when studying or predicting the impacts that an information system has had on process, structure, and performance. The degree and type of impacts would quite naturally be expected to vary with the amount of use that is made of the system. Utilization of a system has also been used as a dependent variable. It has been modeled as an outcome construct that can be influenced by the process of design and implementation and by characteristics of the information system, the task, the individual user and their interaction. Utilization measures are also of great practical significance in a computing environment that is increasingly driven by voluntary users.

For such an important MIS variable as information system use, which has many readily obtainable measures, it is somewhat surprising that the field does not have generally accepted measurement instruments. The lack of such instruments makes the conduct of research in this area more difficult and time consuming. It also means that many measures are quickly developed and inadequately validated. The wide variety of measures that are now employed serves to slow the development of an accumulated body of knowledge on the factors affecting system use and the impacts of system use on elements of the organization.

Before any movement can be made toward standard instruments for measuring utilization of an information system, there are important and difficult conceptual problems that must be resolved. Primary among these is deciding what aspect of use to measure. For example, an individual's use of spreadsheet software can be characterized in several different ways: by the time spent, functions used, or models produced, to name just three. The appropriate selection should be guided in part by the purpose which the measures must serve. 
This paper addresses itself to some of these conceptual problems of measuring utilization. It begins with a review of the past ten years of research literature on factors that affect the use of information systems. From this literature we gain insights into the state of practice of utilization measurement, some of the conceptual problems in this area, and the needs that this varied research has for different measures. The paper then turns to a discussion of the relevant reference theories to which utilization research has turned for theoretical support. The implications of this literature for utilization measurement are examined and we conclude with a discussion of needs for further research.

\section{Data Base of Relevant Articles, 1975-1985}

A total of 17 articles relating various factors to information systems utilization were found by searching 10 journals over the years 1975-1985. These were felt to be representative in terms of methodologies, variable definitions and operationalizations, and findings, and were used for analysis. The Appendix contains a listing of these articles.

Empirical studies include laboratory experiments, quasi-experiments, and case studies. Of these, laboratory experiments are encountered the least frequently in the literature.

\section{Survey of Utilization Research}

The vast majority of research in the utilization area implicitly defines utilization as either the amount of effort expended interacting with an information system or, less frequently, as the number of reports or other information products generated by the information system per unit time. Examples include frequency and number of computer sessions, connect time, time spent using different system functions, number of records updated, and keystrokes or carriage returns. 1

\footnotetext{
TThere are two small bodies of utilization research whose goals are fundamentally different from those of the studies which use effort or information product as a dependent vartable. One of these groups of studies attempts to predict the rate of acceptance of a new technology (i.e. microcomputersi. In these studies. utilization is defined as the number of terminals, microcomputers. printers, or other US component currently used by the organization. There were two such articles found in the literature. Randles (1983) and Ilan and Shapira 11985 iboth developed diffusion models to predict the acceptance rate of a new technology over time. These diffusion models are straightforward applications of well-established theories drawn from new product growth models in marketing (e.g Mahajan and Muller. 1979iand earlier. the Mansfield model of imitation rates of technical change in economics (Mansfield, 1961). The other grnup of studies uses monetary measures to examine empirical relationships between amount of computer system usage and firm characteristics. These studies used dollar figures (Gremillion, 1984) or DP expenditure proportions (Turner. 1982: Delone. 1981) to approxımate degree of MIS usage.
} 
The Mason-Mitroff (1973) research framework provided the impetus for a large stream of empirical research that has studied the relationship between individual utilization of an information system and four general types of independent variables. This research structure is illustrated in Figure 1. The four types of independent variables are design and implementation process variables, information system characteristics, individual differences, and task characteristics.

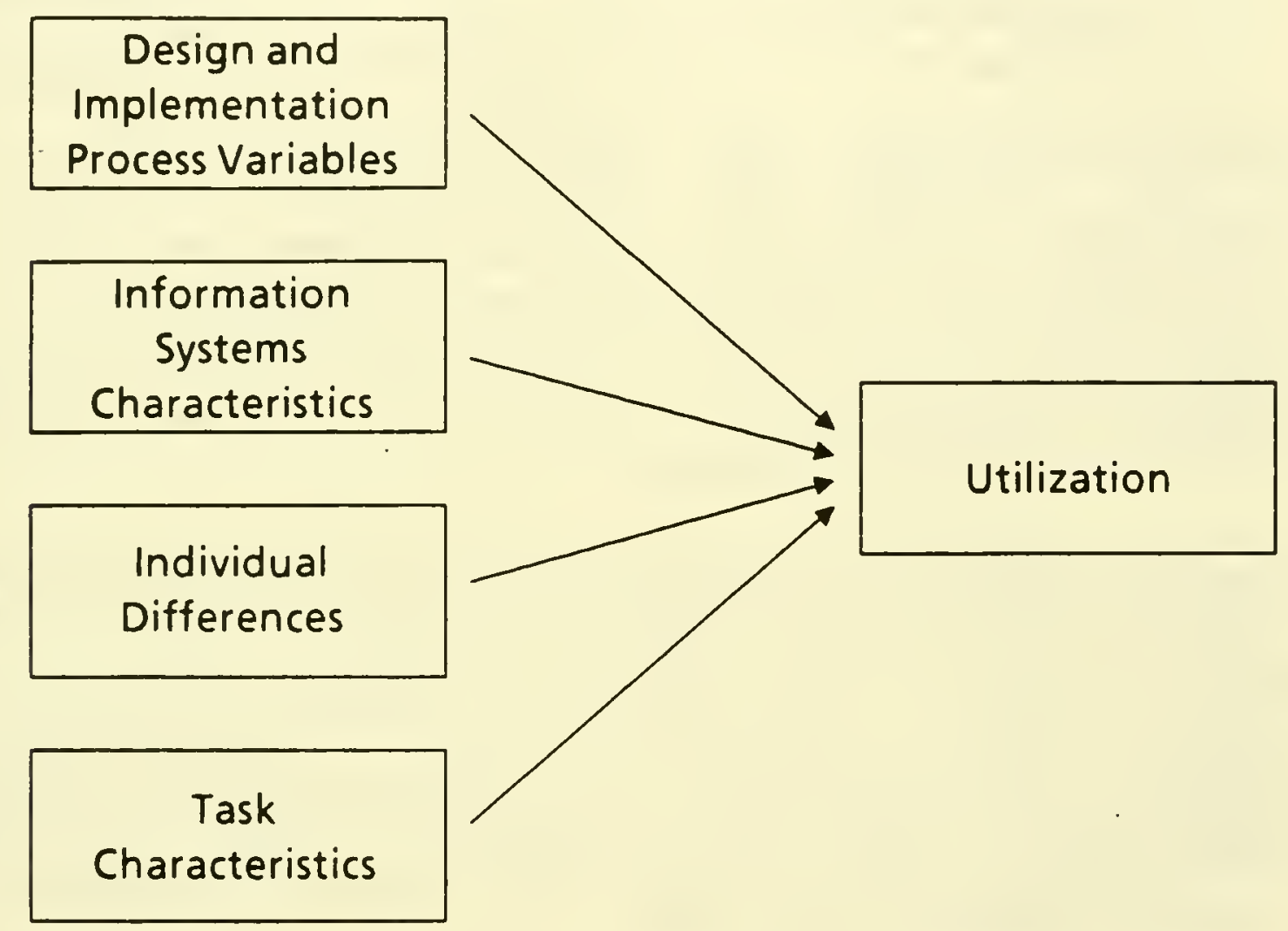

Figure 1. Structure of Utilization Research

Design and implementation process variables refer to the components of the process of introducing information technology into an organization. Examples of these variables studied include amount and quality of training (Schewe, 1976; Fuerst and Cheney, 1982), overall implementation strategy (Gremillion, 1980), accuracy of user expectations (Ginzberg, 1981), support of top management (Schewe, 1976; Fuerst and Cheney, 1982; Robey, 1979; Raymond, 1985), user involvement (Schewe, 1976; Fuerst and Cheney, 1982; Mann and Watson, 1984), understanding of the task 
activities of potential users (Nichols, 1981), and sanctionary power and presence of a third party (De Brabander and Thiers, 1984). In some cases, implementation was operationalized more or less as a binary variable (e.g., Crawford, 1982). In the context of implementation, utilization is employed primarily as a measure of the degree of user acceptance of a new technology.

Information system characteristics affect the efficiency and effectiveness of the user's interaction with a computer system. Some of the characteristics which have been investigated include response time (Schewe, 1976; Fuerst and Cheney, 1982), accuracy and relevancy of output (Schewe, 1976; Srinivasan, 1985; Fuerst and Cheney, 1982; O'Reilly, 1982), stability and security (Srinivasan, 1985), presentation format (Srinivasan, 1985; Fuerst and Cheney, 1982; Ein-Dor, Segev, and Steinfeld, 1982), sophistication of DSS model (Henderson and Schilling, 1985), and user interface (Fuerst and Cheney, 1982; Raymond, 1985). Many of these latter studies have an ergonomic orientation in which system use is employed to assess the efficiency of the man-machine design.

Individual differences affect beliefs, which in turn affect attitudes, intentions, and information system utilization. Examples of individual characteristics which have been studied include age (Fuerst and Cheney, 1982; McCosh, 1984; Culnan, 1983), experience (Fuerst and Cheney, 1982; McCosh, 1984; Culnan, 1983; O'Reilly, 1982; Alavi and Henderson, 1981), educational level (Fuerst and Cheney, 1982; O'Reilly, 1982), and cognitive style (Fuerst and Cheney, 1982). In the context of individual differences studies, there is usually an implicit assumption that utilization is an indicator of MIS success (Zmud, 1979).

Task characteristics refer to the nature of the tasks users must execute. This type of independent variable was considered less often in utilization research than the preceding three. The primary task characteristics which have been investigated are complexity and uncertainty (McCosh, 1984; Culnan, 1983; O'Reilly, 1982; Mann and Watson, 1984). In these types of studies, utilization is employed as a measure of the suitability of the information system to the needs of different types of users.

The purpose of a study was associated with both the nature of the task under study and the means of collecting utilization information. For example, if the activity under study was a defined task, such as editing a file or writing a query, then the objective of the exercise was usually to minimize effort through better design of the 
technology. If it was an undefined or unspecified set of tasks for which the system was used, then more use was usually assumed to be better. More use is taken to indicate the user's belief that the system is beneficial. Less predictably, if the means of gathering utilization information was unobtrusive, such as collecting machine usage statistics, different independent variables were studied than if the utilization was operationalized using self-reported data. These categories of research are briefly reviewed below.

\section{(1) DEFINED TASK, UNOBTRUSIVE OPERATIONALIZATION}

The goal of this type of research is almost always to suggest design choices which will optimize the efficiency of the use of the information system. For example, many studies have been performed to determine whether users can execute a defined task more quickly using menus rather than a command language, or a mouse rather than a keyboard. Note that this type of research is distinct from studies which examine the effect of presentation format or other system characteristics on individual performance (for example, see Ives (1982), and DeSanctis (1984)).

Since the literature in this area is extensive and quite separate from the main body of MIS literature, we will not attempt to survey it here. However, it is simple to describe its general structure. The typical study is a laboratory experiment comparing two systems with different user interface characteristics. The unit of measurement employed is usually a machine usage statistic such as a keystroke or carriage return. Sometimes it is elapsed time. The independent variable is always some sort of system characteristic, such as type of query language used.

\section{(2) DEFINED TASK, SELF-REPORT OPERATIONALIZATION}

Research in this area would presumably have the same goals as the studies in (1). However, no studies were found in this area, possibly because self-reported measures of use would not be accurate enough to covary significantly with the feature of information system design under study. By using objective machine usage statistics, most of the attenuating effects of measurement error and bias can be eliminated.

(3) UNDEFINED TASK, UNOBTRUSIVE OPERATIONALIZATION

All four studies found in this area were quasi-experiments which attempted to establish links between individual attitudes and utilization. The results of the 
studies were somewhat mutually conflicting (see Appendix). This is not surprising, in view of the fact that each of the four researchers employed a different set of measurement units. Robey (1979) used the percentage of records updated. Ginzberg (1981) employed connect time and number and frequency of computer sessions. Schewe (1976) used additional monthly requests for information by managers, and Srinivasan (1985) employed number of accesses per month, connect time, and number of light, average, and heavy users. The range of different measurements observed is probably partly a consequence of the lack of both a cumulative tradition and a generally accepted definition of utilization in this body of literature.

\section{(4) UNDEFINED TASK, SELF-REPORT OPERATIONALIZATION}

Very broadly, the literature in this area attempted to link implementation characteristics and individual differences to the degree of I/S utilization. The results have been rather fragmented, with many different measures being used and many different theories being tested. For example, O'Reilly (1982) found that accessibility of sources of information primarily determines utilization; Fuerst and Cheney (1982) found that user training, accuracy and relevancy of output, and experience are the relevant factors; McCosh (1984) determined that the level of qualifications held by the superior of the main user is the strongest determinant; and Raymond (1985) found a firm's EDP experience to have strong explanatory power. Again, a possible explanation for this fragmentation lies in the absence of a cumulative tradition in the literature.

The predominant methodologies employed in this area were quasi-experiments and informal surveys. A few studies were lab experiments or case based. In general, questionnaires and interviews were used for data collection. The unit of measurement used varied widely. Fuerst and Cheney (1982) employed a series of scale questions concerning general and specific use. Ein-Dor, Segev, and Steinfeld (1982) used past use and intended future use of a PERT system. McCosh (1984) used a five-point scale estimate of system success, with a score of two implying use but ultimate failure. Culnan (1983) employed a series of scale questions concerning end user access. Raymond (1985) used a series of scale questions concerning utilization in general. O'Reilly (1982) employed scale questions pertaining to frequency of use. Two lab experiments operationalized use as a binary variable. 


\section{DISCUSSION}

Two features stand out from this summary of the bulk of the last ten years of utilization literature. One is the lack of an accumulation of knowledge in this area, which is in part attributable to the lack of any standardized measures. This problem can be traced back to a lack of underlying theory to guide the choice of measures. The other is the relatively large proportion of studies which employed self-reported utilization measures, even though unobtrusive measures are often obtainable and, as a rule, more accurate.

In the absence of an underlying theory, the research methodology rather than the theory tends to drive the choice of utilization measure, which is inappropriate. This problem is exacerbated when a single utilization measure is used in studies involving multiple independent variable types. As will be discussed later, consistency of measurement, and thus a cumulative tradition, can only be achieved if the proper reference theory, rather than the research methodology, guides utilization definition and measurement. In the next section we will discuss several relevant reference disciplines in detail.

Unobtrusive utilization measures have been employed infrequently for several reasons. One is that machine usage statistics are often more difficult to obtain from organizations than completed questionnaires or interviews. If more sophisticated usage statistics are desired, it may even be necessary to alter the characteristics and/or performance of the information system extensively. Another reason is that often researchers can only collect utilization data some time after the utilization has taken place. Unfortunately, post hoc self-report data tends to be weaker and less accurate than unobtrusive data.

\section{Reference Theories for Utilization Measurement}

All the studies we have reviewed have a similar structure; some aspects of system use is hypothesized to be affected by some other aspects of the design and implementation process, or by characteristics of the information system, the task, the individual user or their interaction. But what aspects of system use are most appropriate to measure? This depends in large part upon which independent 
variable is under study. Different independent variables will alter utilization in different ways. Utilization needs to be defined and operationalized in terms that can measure these effects best. This suggests that it is the independent variables employed in utilization studies which should determine the choice of reference theory. In this section we turn to a brief discussion of some theories that correspond to different types of independent variables employed in utilization research and the implications of these theories for utilization measurement.

A review of the literature revealed three reference theories that are useful for linking various types of independent variables with utilization. In the case of implementation variables, Keen (1981) argued that the Lewin-Schein (Schein, 1969) model of change management underlies much of the MIS implementation literature. In the case of individual differences and information systems variables, two other theories are suggested by Zmud's (1979) model linking individual differences to MIS success. One theory, linking individual differences with MIS user attitudes and involvement, is Fishbein's (1979) theory of reasoned action. The other, which links individual cognitive differences to desirable MIS design characteristics, is the theory of ergonomics.

In summary, the three theories (and the different determinants of utilization they explain) which we will review are as follows: the Lewin-Schein model of change management (implementation variables), the Fishbein theory of reasoned action (individual differences variables), and ergonomic theories of man-machine interaction (individual differences and information systems variables). These three reference theories underlie a great deal of the utilization research. Since task characteristics have received so little attention in the utilization literature, we will not discuss any reference theories corresponding to that area. The primary goal of this discussion is to identify the relevant utilization definitions each reference theory suggests. A secondary goal is to comment on how the utilization definitions are linked to performance.

\section{(1) IMPLEMENTATION VARIABLES - LEWIN-SCHEIN MODEL OF CHANGE MANAGEMENT}

The Lewin-Schein (1969) model of implementation and Kolb and Frohman's (1970) extension of it constitute the implicit theory used in much of the MIS implementation literature. A related theory (Rogers, 1962) of acceptance of 
innovations parallels the Lewin-Schein framework. In these models, implementation is viewed as a three-stage process. In the first stage, the organizational environment is "unfrozen". By this we mean a climate and contract for a change in the environment (in this case, an MIS implementation) is created. For example, a climate for change exists when users are made to feel that the organization needs an MIS in order to improve performance. In the second stage, the change is actually implemented. In the third stage, the change is institutionalized, that is, it actually becomes an integral part of the organization.

These models equate implementation success with the degree to which the MIS is institutionalized in the organization. Utilization is often used as a surrogate measure of the degree of institutionalization - the more a system is used the more it becomes an integral part of the organization. There are at least three aspects of system use that are most relevant to the institutionalization construct. One is the degree to which users are dependent upon the MIS after it has been implemented. That is, if the MIS were suddenly to disappear, would its absence be missed by the organization? Another is the extent to which users feel an ownership for the MIS. Do they feel that they have control of the system, or does the MIS department dictate how it is used? A third is the degree to which use of the MIS is routinized, that is, used as part of the standard operating procedure of the organization. These are the three aspects of information system utilization most relevant to implementation research.

Note that the concept of institutionalization is very different from the concept of performance. Indeed, institutionalization of an MIS can occur without there being any performance change observed in the organization. We will explore the link to performance in greater detail in Section V.

\section{(2) INDIVIDUAL DIFFERENCES - FISHBEIN'S THEORY OF REASONED ACTION}

The theory of reasoned action is a model widely employed in research that links beliefs and attitudes to behavior. It is illustrated in Figure 2. The theory suggests that the use of an information system is best predicted by an individual's intention to use the system. This intention is determined by some weighted combination of the individual's attitude toward using the system and his or her subjective assessment of the social acceptability of this behavior. Attitude toward use is in turn determined 
by the individual's beliefs about the consequences of using the system and social acceptability is determined by assessing the opinions of some referent group.

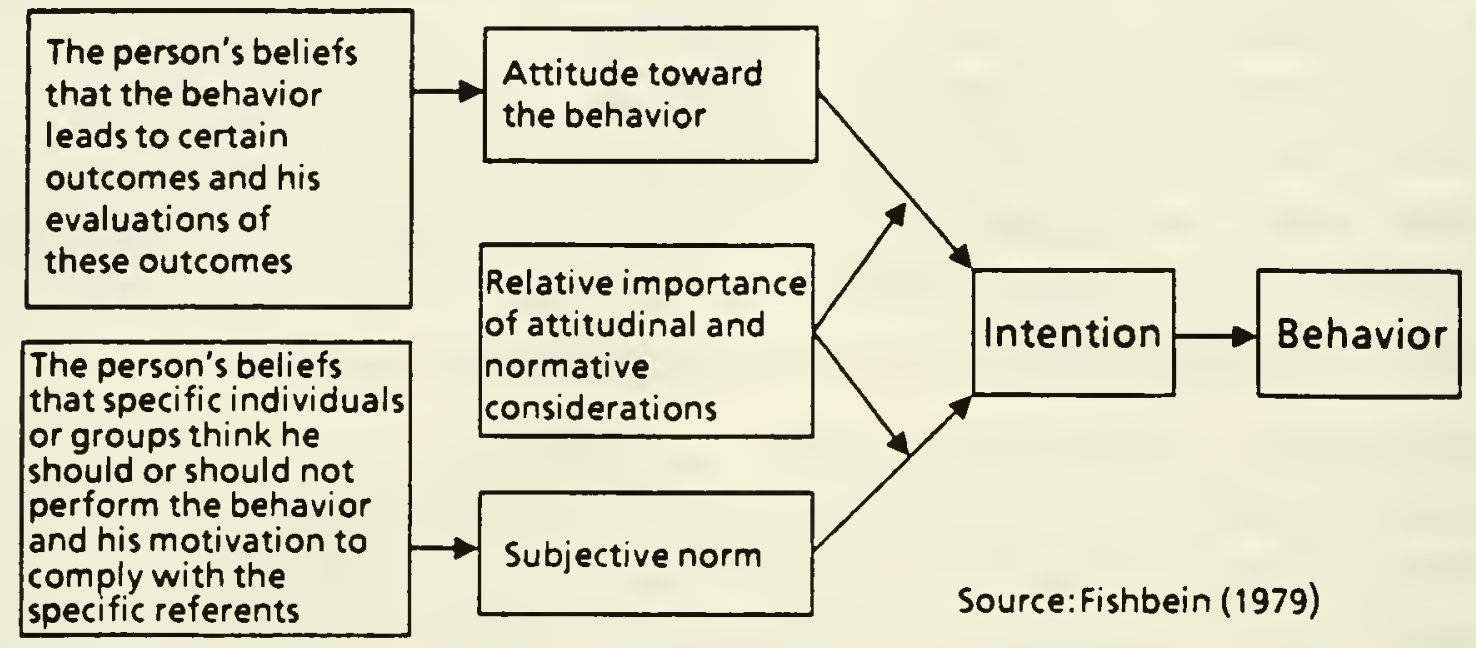

Figure 2. Theory of Reasoned Action

Thus, according to this theory, whether or not an individual uses an information system can be traced back to his or her beliefs about the benefits that will derive from its use. Individual differences, such as age, computer experience, or educational background affect these beliefs which in turn affect whether or not a system is used through attitudes, norms, and intentions. Here again the reference theory can shape our understanding of what aspects of system utilization are important to measure. In applying this particular theory, we would want to define utilization as the active use of the system or some aspect of the system and to model it as a binary variable, use and non-use of the system. This definition of utilization is very different from the definition that is directly relevant to implementation research. There is no direct relationship between use, as defined through the theory of reasoned action, and performance. Whether use or non-use of a system results in performance improvements depends upon the business context and a myriad of other intervening variables.

\section{(3) INDIVIDUAL DIFFERENCES AND INFORMATION SYSTEMS CHARACTERISTICS - ERGONOMICS}

Broadly stated, one of the goals of ergonomics is to provide for efficient man-machine interfaces that are suited to the physical and cognitive capabilities of man. Thus ergonomics has two related goals, to reduce human physical effort through efficient 
design and to reduce cognitive effort through designs that are easy to use and robust. Attainment of both these goals can be unobtrusively measured with utilization variables.

In information systems design research, more attention has been focused upon reducing physical effort than cognitive effort, perhaps because the associated utilization measures are easier to obtain. Measures of physical effort include such constructs as keystrokes, carriage returns, and elapsed time for a fixed task. Measures of cognitive effort are often difficult to obtain, so surrogates such as error rates and requests for help are often used.

The link between utilization in the sense of physical and cognitive effort and performance is relatively straightforward; minimizing effort expended to execute a fixed, defined task improves performance because it saves time. This allows the user to spend more time engaged in other activities.

\section{Conclusions: Needs for Future Research}

Having reviewed the utilization literature and discussed three relevant reference theories, we now turn to recommendations for future research.

\section{UTILIZATION AS A DEPENDENT VARIABLE: DEFINITION AND MEASUREMENT}

The research we have surveyed indicates that linkages between utilization and its determinants are not well understood. As Section III showed, the literature is somewhat fragmented, and in some cases conflicting results have been obtained. The lack of theoretical understanding has in turn caused methodological problems. Many utilization studies have measured the relationship between various independent variables and utilization directly without paying attention to intervening variables. For example, several studies have investigated the relationship between individual differences and utilization without controlling for any intervening attitudinal variables, thereby limiting the strength of the results.

How can the determinants of utilization be better understood? The first step is to recognize that utilization is a multidimensional variable, and that different definitions of utilization will apply depending on the process under study, whether it 
be implementation, reasoned action, man-machine interaction, or some other process. If the process to be studied has been determined, the second step is to use the applicable reference theory to guide research design. Reference theories can aid both in identifying appropriate independent and intervening variables to relate to utilization and in providing definitions of utilization which will suggest good operationalizations.

As important as the chosen definition of utilization is the definition of information technology which is chosen. Here again, it is important to select a definition which is appropriate for the theory. For example, from the perspective of the theory of reasoned action, information technology can be characterized as a system which provides potentially useful functions. This is because the theory predicts that it is beliefs about the consequences of using the system's functions which ultimately determines utilization.

One consequence of the lack of consistency in utilization definitions in MIS research is the lack of consistency of utilization measures as well. It has been pointed out that this lack of measurement consistency often makes it difficult to compare different studies in this area. One way to alleviate this problem is to adopt standardized utilization measures. However, adopting standardized measures would require a standardized definition of utilization as well. This is inappropriate, since as discussed above, utilization is process dependent. The best we could hope for would be to adopt standardized measures within the context of a single theory based on the definition of utilization the reference theory suggests. For example, an instrument based on the Lewin-Schein framework could be developed which would measure user dependency and ownership towards an MIIS.

A second issue concerns the use of objective utilization measures. Even though machine usage statistics are routinely logged and readily accessible (at least in the case of mainframe computer systems), thus far they have been employed far less frequently than self-reported measurements in the literature. It is recommended that researchers use machine usage measures rather than the more subjective selfreported measures whenever possible, since as a rule objective measures are more accurate. Machine usage measures can be made even more accurate by imposing controls. For example, if connect time is the measure being used, users could be logged off automatically during extended idle periods. 
Care must be exercised in the selection of objective machine usage measures, however. For example, if effort is the construct being measured, it is not appropriate to use the number of information products such as reports as the operationalization. The reason is that information products are in fact a function of effort and the characteristics of the information system rather than a measure of the effort itself.

\section{UTILIZATION AS AN INTERVENING VARIABLE}

Although this paper has focused on utilization as a dependent variable, it is appropriate to examine the role of utilization in a broader context briefly. Doing so will serve to place the employment of utilization as a dependent variable in perspective, as well as to suggest additional avenues for future research.

In a theory linking information technology and performance, utilization can be viewed as an intervening variable (see Figure 3 ). That is, utilization is partially determined by information technology variables, and is also one of the many variables which ultimately affects performance. We will refer to theoretical relationships between information technology and utilization as backward linkages, and between utilization and performance as forward linkages. As Figure 3 shows, neither backward or forward linkages are necessarily direct. For example, according to the theory of reasoned action, utilization is determined by an individual's intention to use a system, rather than directly by the availability of the technology. Similarly, one could argue that utilization affects performance by means of organizational structural changes. This paper has so far addressed itself exclusively to improving our understanding of backward linkages; possible steps towards a better understanding of forward linkages are discussed below.

It is clear that forward linkages must exist if a system is to affect performance, since information technology cannot have an impact on performance if it is not used in some way. However, the nature of these linkages is not at all clear. There are cases in which increased utilization actually leads to a degradation in performance, for example, when there is a fixed task to perform and the system is designed inefficiently such that it takes more effort to complete the task than is necessary, or the system is so personally desirable to users that they expend considerable effort using the system in nonproductive ways. Consequently, utilization alone is not sufficient to predict performance accurately, which means that forward linkages are 


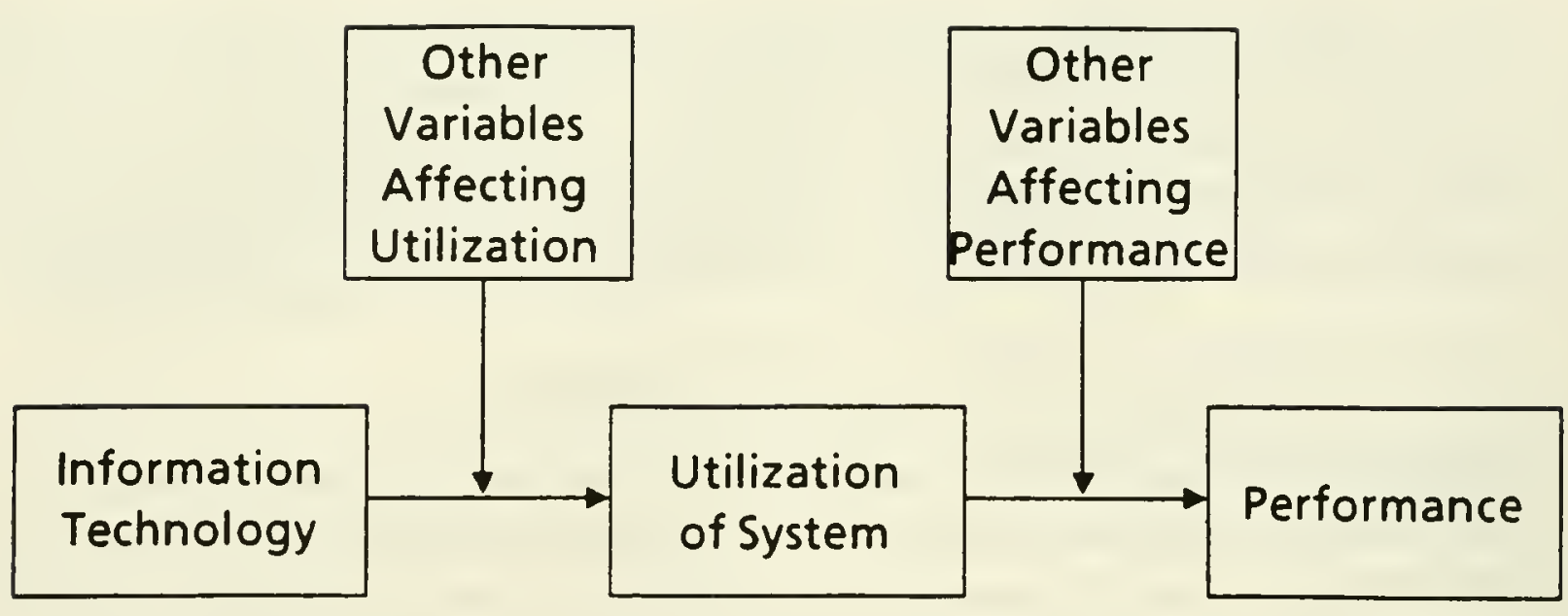

Figure 3. Utilization as an Intervening Variable

bound to be complex. Thus, utilization is a necessary but insufficient condition for a system to affect performance.

This complexity of forward linkages has an important implication for utilization research. Some of the studies performed to date have assumed that utilization of an information system is a surrogate measure of its effectiveness or success. The preceding discussion suggests that to achieve a better understanding of the link between information technology and performance, it would be fruitful to view utilization as an independent variable affecting performance, rather than an indicator of performance itself. Employment of utilization as a dependent variable should be restricted to the context of a reference theory such as one of those previously discussed.

If utilization is treated as an independent variable affecting performance, then there are at least two ways in which it can be defined and measured. One is to identify the components of performance which are of interest and measure the facets of utilization which correspond to these components. For example, if we are interested in the effect of information technology on communication, then clearly we should focus on utilization of the communications-oriented features of a system as opposed to utilization of some other information systems function. Another is to use the theoretical factors which affect performance to suggest appropriate 
operationalizations. These techniques can also be used in the case where the ultimate dependent variable is something other than performance, such as organizational structural change.

It should be noted that the methods for measuring utilization as an independent variable are sometimes completely different from those used for measuring it as an dependent variable. For example, to measure the effect of utilization on individual performance, it may be useful to measure utilization in terms of the distribution of computer time spent performing various functions such as spreadsheet and electronic mail, but it would not be useful to use this particular measure in the context of any of the reference theories discussed above. This is a consequence of the difficulty of developing a simple and accurate theory linking information technology and performance.

Although understanding the nature of both backward and forward linkages is an important step, taken together the two linkages do not provide a complete and consistent view of the significance of utilization as an intervening variable. Constructing a continuous theoretical path from information technology through utilization to performance may still be difficult. Operational definitions of utilization obtained from performance components will not necessarily correspond to those obtained through identifying utilization determinants.

In summary, utilization is an important intervening variable in the link between information technology and performance. Although much valuable research has been performed, utilization is still not well understood or well measured. Drawing upon reference theories for definitions and operationalizations will move the MIS field closer to to achieving this. It is difficult to trace a clean theoretical path between information technology and performance with utilization, but impossible to trace such a path without it. 


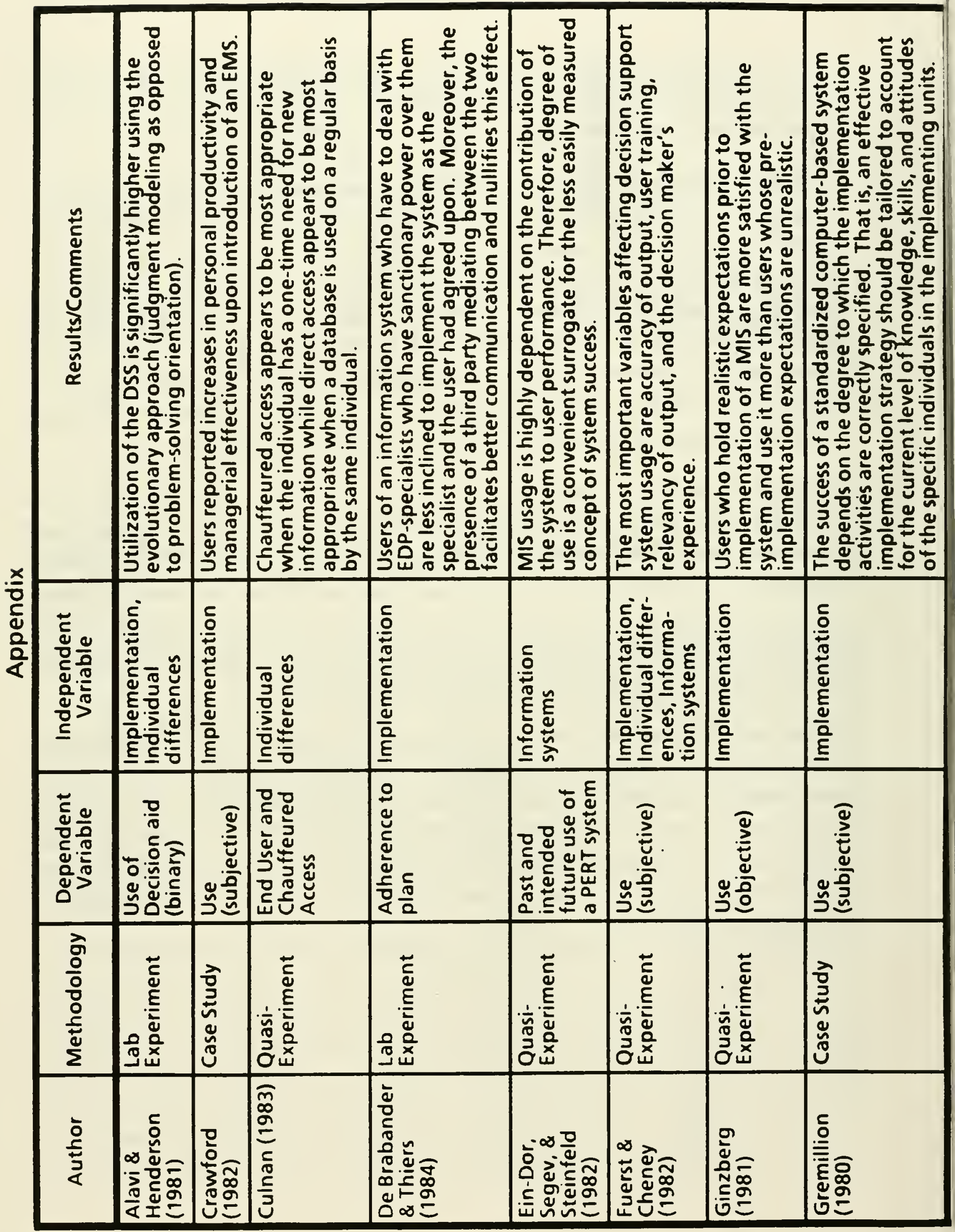




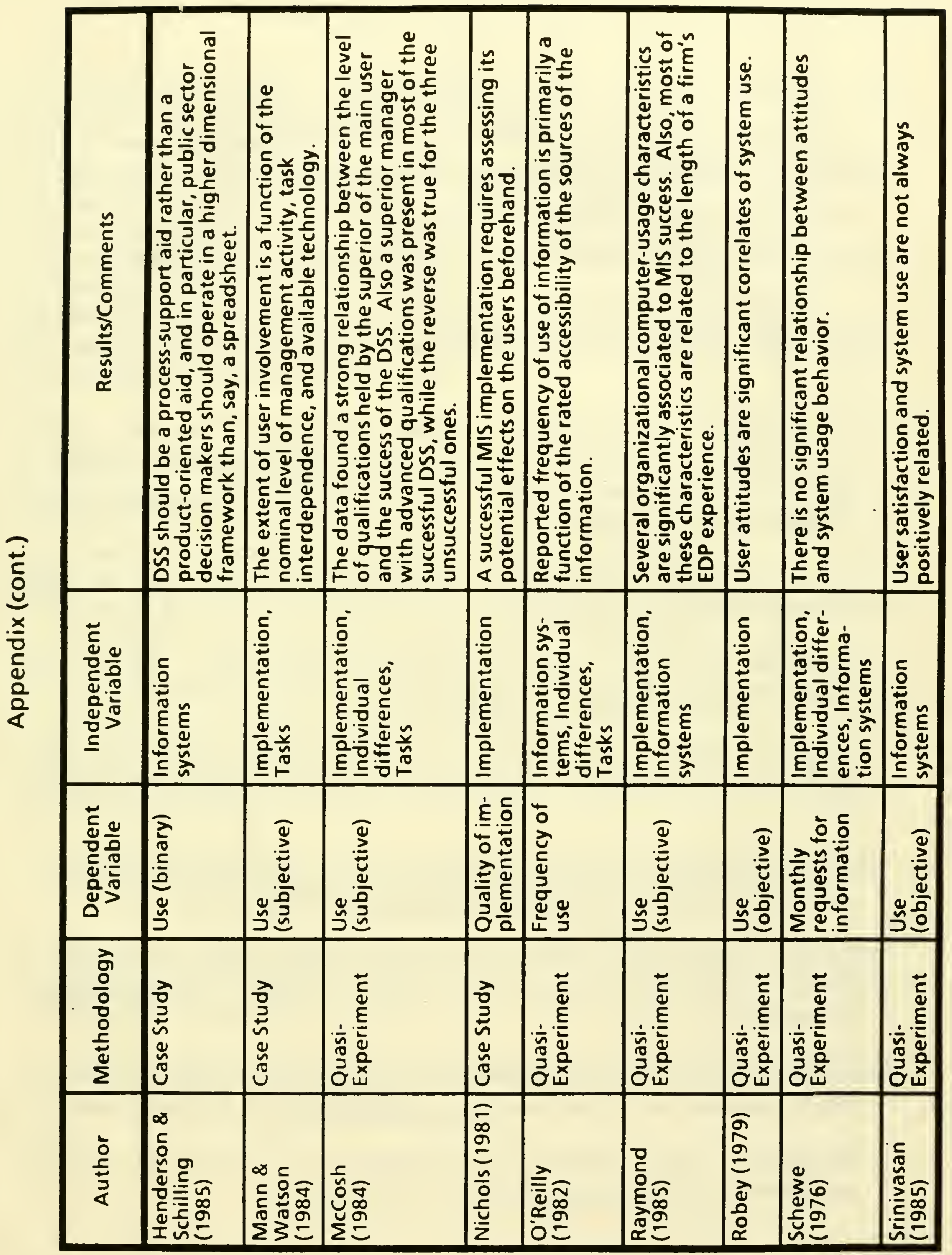




\section{References}

Alavi, M., and Henderson, J. (1981), "An Evolutionary Strategy for Implementing a Decision Support System," Management Science, November 1981, pp. 1309-1323.

Crawford, A. (1982), "Corporate Electronic Mail -- A Communication-Intensive Application of Information Technology," MIS Quarterly, September 1982, pp. 1-13.

Culnan, M. (1983), "Chauffeured Versus End User Access to Commercial Databases: The Effects of Task and Individual Differences," MIS Quarterly, March 1983, pp. 55 67.

De Brabander, B. and Thiers, G. (1984), "Successful Information System Development in Relation to Situational Factors Which Affect Effective Communication Between MIS-Users and EDP-Specialists," Management Science, February 1984, pp. 137-155.

Delone, W. (1981), "Firm Size and the Characteristics of Computer Use," MIS Quarterly, December 1981, pp. 65-77.

DeSanctis, G. (1984), "Computer Graphics as Decision Aids: Directions for Research," Decision Sciences, Vol. 15, pp. 463-487.

Ein-Dor, P., Segev, E., and Steinfeld, A. (1982), "Use of Management Information Systems: An Empirical Study," Conference on Information Systems, 1982, pp. 215 228.

Fishbein, M. (1979), "A Theory of Reasoned Action: Some Applications and Implications," Nebraska Symposium on Motivation, 1979, pp. 65-116.

Fuerst, W., and Cheney, P. (1982), "Factors Affecting the Perceived Utilization of Computer-Based Decision Support Systems in the Oil Industry," Decision Sciences, October 1982, pp. 554-569.

Ginzberg, M. (1981), "Early Diagnosis of MIS Implementation Failure: Promising Results and Unanswered Questions," Management Science, April 1981, pp. 459-478.

Gremillion, L. (1980), "Managing the Implementation of Standardized Computer Based Systems," MIS Quarterly, December 1980, pp. 51-59. 
Gremillion, L. (1984), "Organization Size and Information System Use: An Empirical Study," Journal of MIS, Fall 1984, pp. 4-17.

Henderson, J., and Schilling, D. (1985), "Design and Implementation of Decision Support Systems in the Public Sector," MIS Quarterly, June 1985, pp. 157-174.

Ilan, Y., and Shapira, Z. (1985), "The Introduction and Use of Microcomputers by Professionals In An Industrial Corporation".

Ives, B. (1982), "Graphical User Interfaces for Business Information Systems," 프 Quarterly, Special Issue 1982, pp.15-42.

Keen, P. (1981), "Information Systems and Organizational Change," Communications of the ACM, January 1981, pp. 24-33.

Kolb, D. and Frohman, A. (1970), "An Organization Development Approach to Consulting," Sloan Management Review, Fall 1970, pp. 51-65.

Mahajan, V., and Muller, E. (1979), "Innovation, Diffusion and New Product Growth Models in Marketing," Journal of Marketing, Fall 1979, pp. 55-68.

Mann, R., and Watson, H. (1984), "A Contingency Model For User Involvement in DSS Development," MIS Quarterly, March 1984, pp. 27-38.

Mansfield, E. (1961), "Technical Change and the Rate of Imitation," Econometrica, 29 (October), 741-766.

Mason, R., and Mitroff, I. (1973), "A Program for Research on Management Information Systems," Management Science, January 1973, pp. 475-487.

McCosh, A. (1984), "Factors Common to the Successful Implementation of Twelve Decision Support Systems and How They Differ From Three Failures," Systems, Objectives, Solutions, V. 4, pp. 17-28.

Nichols, M. (1981), "A Behavioral Analysis for Planning MIS Implementation," MIS Quarterly, March 1981, pp. 57-66. 
O'Reilly, C. (1982), "Variations in Decision Makers' Use of Information Sources: The Impact of Quality and Accessibility of Information," Academy of Management Journal, No. 4 1982, pp. 756-771.

Randles, F. (1983), "On the Diffusion of Computer Terminals in an Established Engineering Environment," Management Science, April 1983, pp. 465-476.

Raymond, L. (1985), "Organizational Characteristics and MIS Success in the Context of Small Business," MIS Quarterly, March 1985, pp. 37-52.

Robey, D. (1979), "User Attitudes and MIS Use," Academy of Management Journal, No. 3, pp. 527-538.

Rogers, E. (1962), Diffusion of Innovations, New York: Free Press, 1962.

Schein, E. (1969), Process Consultation: Its Role in Organization Development, Reading, Mass.: Addison-Wesley, 1969.

Schewe, C. (1976), "The MIS User: An Exploratory Behavioral Analysis," Academy of Management Journal, December 1976, pp. 577-590.

Srinivasan, A. (1985), "Alternative Measures of System Effectiveness: Associations and Implications," MIS Quarterly, September 1985, pp. 243-253.

Turner, J. (1982), "Firm Size, Performance, and Computer Use," Conference on Information Systems, 1982, pp. 109-120.

Zmud, R. (1979), "Individual Differences and MIS Success: A Review of the Empirical Literature," Management Science, October 1979, pp. 966-979. 





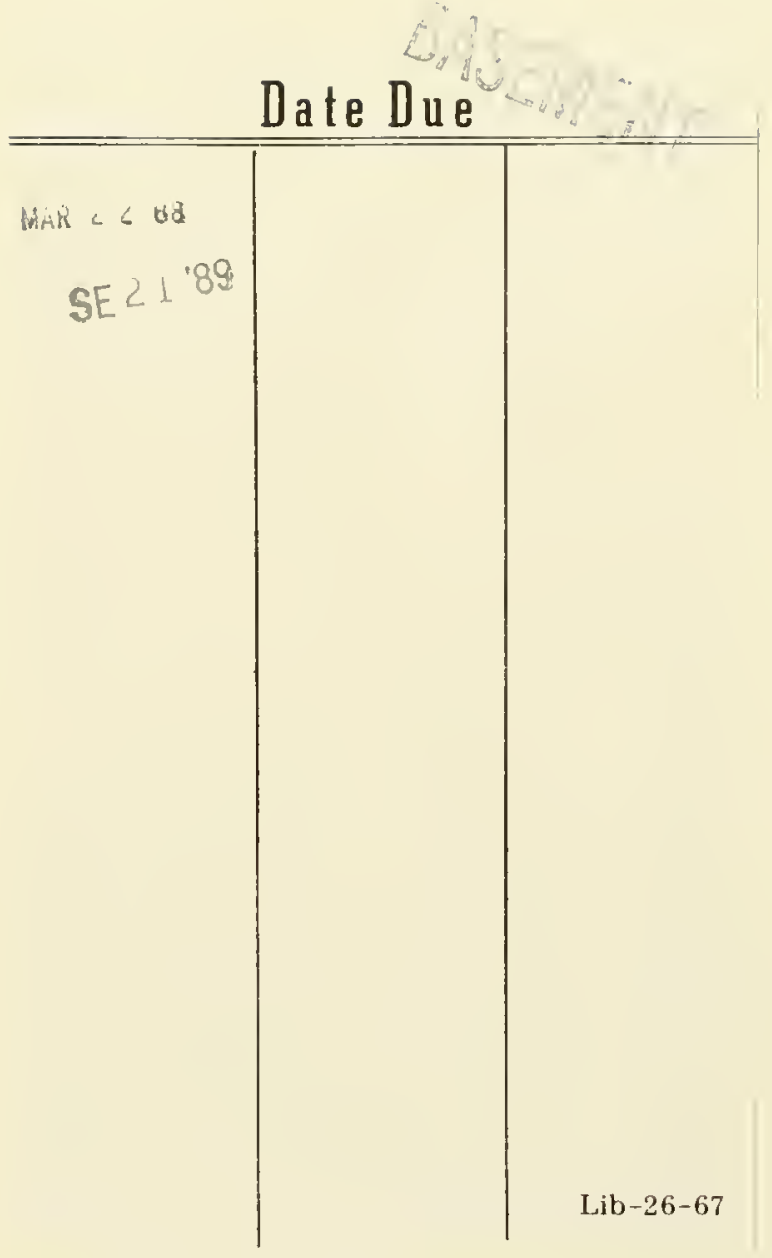




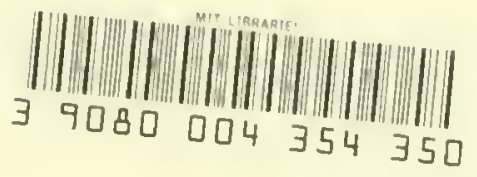


